\title{
Infantile Haemangioma with Neonatal Systemic Lupus Erythematosus, Rare Combination, Case Report and Review of Literature. Experience from king Abdulaziz Medical City, Riyadh Saudi Arabia
}

\author{
Hayat Ibrahim Aljutaily* \\ Assistant professor of pediatrics, college of Medicine and health Sciences, Al Qassim University, Saudi Arabia
}

Submission: December 23, 2018; Published: January 16, 2019

*Corresponding author: Hayat Ibrahim Aljutaily, Assistant professor of pediatrics, college of Medicine and health Sciences in Unizah (Al Qassim University), Saudi Arabia

\begin{abstract}
Combination of Infantile haemangioma, multiple cardiac anomalies, congenital heart block secondary to maternal systemic lupus erythematosus is a rare event. Herewith, we present 30 weeks neonate women known case of systemic lupus erythematosus for five years. He delivered by emergency cesarean section when he developed severe bradycardia due to heart block diagnosed intrauterine as complication of long-term use of dexamethasone and developed infantile haemangioma. Multidisciplinary team was formed for the management of the cases, including cardiologist, dermatologist and neonatologist. From the cardiac side propranolol contraindicated in presence of complete heart block so the plan to wait for pacemaker insertion then to start medication. Once pacemaker inserted the propranolol was started and the lesion was started to decrease inside with no ulceration.
\end{abstract}

Keywords: Infantile haemangioma; Systemic lupus erythematosus; Propranolol, Heart block

\section{Introduction}

Systemic lupus erythematosus (SLE) is a multisystem and complex disease. It has been established that SLE may increase pregnancy complications [1], and remains a disease associated with significant fetal and maternal complications [2-4].

Infantile haemangioma ( $\mathrm{IH})$ has been reported in $3-10 \%$ of all new born as the most common vascular tumor in infancy $[5,6]$. Risk factors reported with IH are female sex, Caucasian race, prematurity, family history of IH and multiparous [5,7].

The usual clinical course includes an initial engorgement followed by regression and it usually regresses spontaneously and so should be kept under close observation and active intervention is performed only if the lesion is very extensive [8]. Treatment modalities include topical [9] and oral beta blockers, [10-13] local and oral steroids, [14,15] surgical excision, immunotherapy, [16] and embolization [17]. Corticosteroids represent the treatment of choice in cases of reactivation of SLE during pregnancy and can be used as prednisone or prednisolone. These compounds are inactivated by the enzyme 11- $\beta$ - hydroxysteroid dehydrogenase 2 and reduce fetal exposure to approximately $10 \%$ of maternal dosage [18]. Therefore, the use of these drugs does not replace the use of betamethasone or dexamethasone when they are indicated for fetal lung maturation.

These autoantibodies may damage the developing tissue and increase the risk of bearing infants with neonatal lupus erythematosus (NLE). Neonatal lupus syndromes refer to a clinical spectrum of cutaneous, cardiac, and systemic abnormalities observed in newborn infants. The condition is rare, usually benign and self-limited, but may sometimes have serious consequences [19].

Approximately $98 \%$ of affected infants have maternal transfer of autoantibodies. However, only $1-2 \%$ of mothers with these autoantibodies have neonates with NLE, regardless of whether the mothers are symptomatic or not [20].

The diagnosis is usually made based on the clinical features and the demonstration of neonatal lupus associated antibodies in the serum of the mother or affected infant. The most common clinical manifestations of NLE are, in decreasing order of frequency, dermatologic, cardiac, and hepatic abnormalities. 
Some infants may also have hematologic, neurologic, or splenic abnormalities [20]. The most serious complication in the neonate is complete heart block (CHB), which occurs in approximately $2 \%$ of such pregnancies. CHB can be devastating for these babies: over $60 \%$ require a pacemaker (and recurrent changes as the child grows), $10 \%$ will develop cardiomyopathy late after birth despite pacemaker placement, and the 10 -year mortality rate is $20-35 \%$ (20).

Current standard of care in SLE pregnancy includes Doppler studies of uterine arteries and umbilical artery, which are helpful to assess placental function and to exclude the occurrence of complications such as PE and fetal distress [21]. Uterine Doppler studies are useful as screening test for PE and the 24th week is the best moment for the evaluation. Abnormal uterine artery Doppler studies have been identified in patients with SLE with posterior fetal loss, PE, IUGR, and preterm labour [22,23-24].

Herewith, we report a case of SLE mother delivered preterm because severe bradycardia due to heart block as complication of SLE with accidental finding of infantile haemangioma.

\section{Case Report}

A 35 years old women known case of systemic lupus erythematosus (SLE) for 5 year and on regular dexamethasone. She is para 2, her first pregnancy ended cesarean section due to failure to progress. Concerned pregnancy was preterm, 30 weeks delivered by emergency CS because he developed severe bradycardia due to heart block diagnosed intrauterine.

When she noticed decrease fetal movement, an ultrasonography revealed single viable foetus with heart rate of 50/min. Apgar score was 8 in first min, 9 in $5^{\text {th }}$ min. 9 in $10^{\text {th }}$ min with birth weight $1.3 \mathrm{~kg}$.
Baby intubated and management of respiratory distress syndrome and sepsis and along with doubtamine dobutamine injection as inotropic support in the short-term treatment of cardiac decompensation and isoproterenol for the treatment of bradycardia.

Imaging study with echocardiography showed multiple cardiac anomalies; congenital heart block secondary to maternal SLE, moderate atrial septal defect (ASD) secondum, large patent ductus arteriosus (PDA) and mildly dilated ascending aortic route. Good left ventricular systolic function was reported.

Two days later the patient was seen by cardiologist who advised to monitor the vital signs till the patients off of inotropes and ventilation and recovered from RDS. At that time heart rate still $50-60 / \mathrm{min}$ average reaching $40 / \mathrm{min}$ with maintain blood pressure (BP). The discussion started with cardiology team about pacemaker insertion waiting for baby stabilization and to be weaned off HFOMV.

At age of 16 days the baby developed solitary well defined erythematous plaque over the lower half of the right ear extended to the neck measured abound $4 \times 2.5 \mathrm{~cm}$, no ulcer or bleeding noted and considered as infantile haemangioma.

Multidisciplinary team was formed for the management of the cases, including cardiologist, dermatologist and neonatologist. From the cardiac side propranolol contraindicated in presence of complete heart block so the plan to wait for pacemaker insertion then to start medication. During follow up from dermatology they labelled the lesion rapidly growing infantile haemangioma and likely to get larger and larger diagnosed as right parotid haemangioma. Neck ultrasound findings related to infantile parotid haemangioma (measuring $3 * 1.2 * 2.7$ ). (Figure 1\&2).

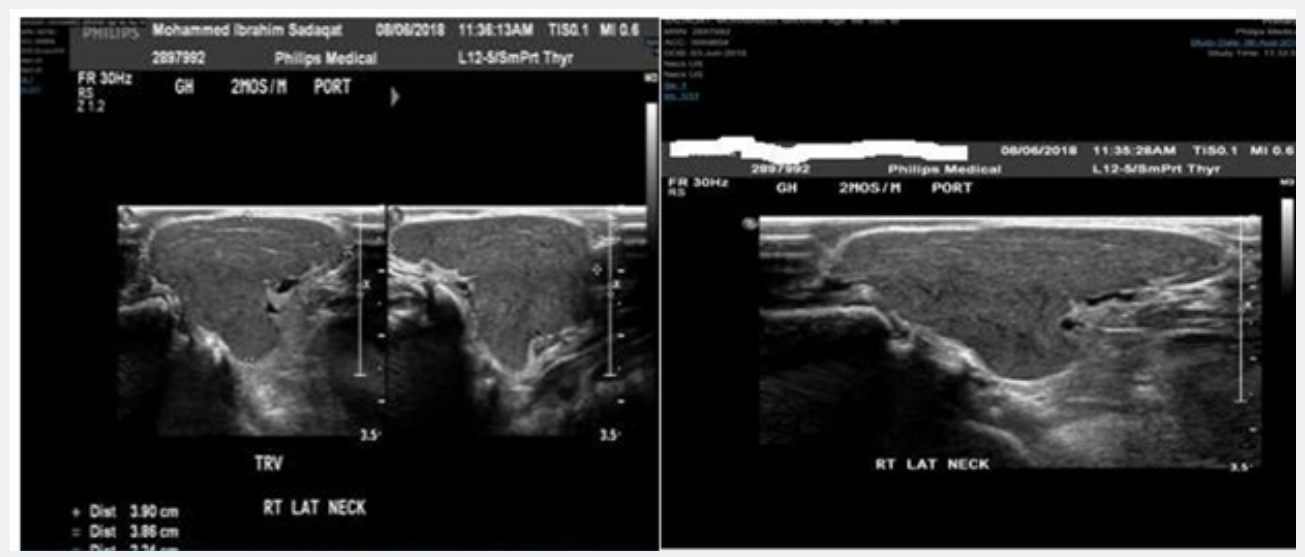

Figure 1\&2: Neck ultrasound findings related to infantile parotid haemangioma (measuring $3 * 1.2 * 2.7$ ).

The multidisciplinary team debated on the best option for treatment. Likely to enlarged and he will benefit from propranolol. Other medication options for this lesion are high dose steroid but the baby is premature and admitted to $\mathrm{R} / \mathrm{O}$ sepsis and there is other side effect of steroids infection, growth retardation. And $3^{\text {rd }}$ line is Vincrestin. But the dermatologist keeps asking and insisting for propranolol as the best and safest option for our patient and they advise the

Pacemaker to be installed as soon as possible so we can start it to prevent complications such as airway obstruction, ulceration and bleeding. 
And they are following the lesion and picture, measurement was taken frequently the size of the lesion increasing, now it is obstructing ear canal and pushing ear lobe outwards with possibility of obstructing the air canal. Because of complex situation neonatologist decide to state high dose steroid and decrease it gradually when pacemaker inserted. Then pacemaker was inserted patient started trial of atenolol for one week and later changed to propranolol $2 \mathrm{mg} / \mathrm{kg} /$ day. Neck US repeated showed a well-defined soft tissue mass with internal vascularity that is measuring $2.7 \times 1.6 \mathrm{~cm}$ (previously $2.9 \times 1.6 \mathrm{~cm}$ ) arterial and venous wave form likely representing haemangioma. The patient remained for 45 days in propranolol and discharged home with same dose of medication for one year and with follow up with dermatology, cardiology and neonatology department.

\section{Discussion}

Infantile haemangioma is a rare presentation that requires coordinated multidisciplinary intervention, and this was crucial to achieve a successful outcome. This case was managed in a tertiary specialist paediatric centres in order to have optimal care. Through all the management process was based on team of multidisciplinary with variety of essential specialty consultation.

This condition has been described in this case with preterm and parous woman. This what typically noted in the literature which indicated that it is high incidence of preterm delivery. It can be spontaneous, usually related to premature rupture of membranes, or iatrogenic as an option to protect the health of the mother and/or the fetus, like in cases of PE or fetal distress [19]. In addition, SLE pregnancies are considered high risk condition and recent studies reinforce the importance of planning the pregnancy.

The diagnosis of neonatal heart block due SLE was well established with approach well recognized and appreciated from all the team member. In the literature that the most serious complication in the neonate is complete heart block where the pacemaker is required in more than $60 \%$ and unfortunately

About $10 \%$ intend to develop cardiomyopathy late after birth despite pacemaker placement [20]. Initially assessment of our case showed rapidly progressing INH. With multiple risks of ulceration, bleeding and compression air way. Due to possibilities of such risk debate with the multidisciplinary team was started to answer the question did we start propranolol in spite of heart block as it's the only available management of haemangioma. The cardiology view never to start propranolol till to insert pacemaker. Neonatology view until to resolve the sepsis and preparation well for pacemaker. Once pacemaker inserted the propranolol was started and the lesion was started to decrease inside with no ulceration (Figure 3\&4). Discharged home on the propranolol for one year before that he was on high dose of steroid.

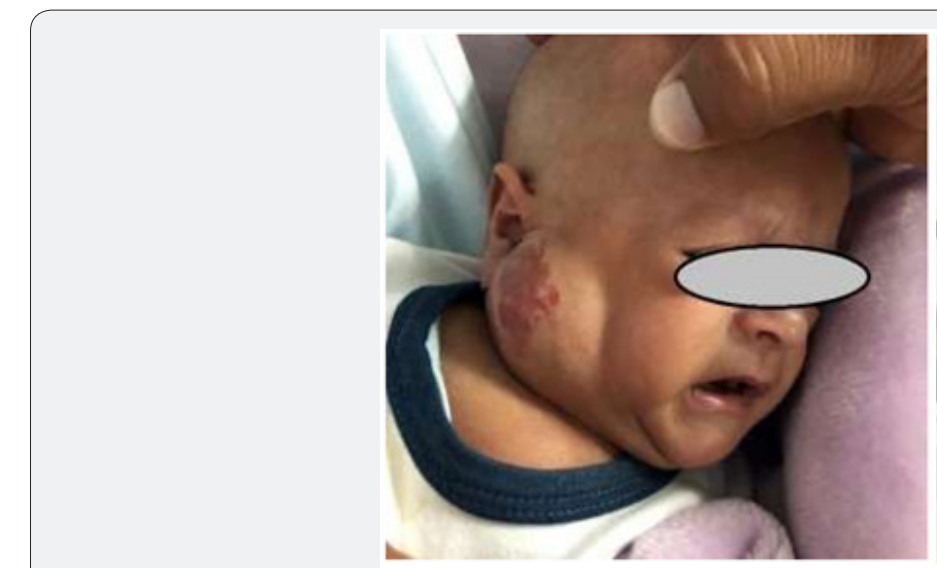

Figure 3\&4: Infantile haemangioma pre and post treatment.

The unique is how to deal with heart block with INH and to deal with such challenge. We successes to achieve satisfactory outcome for this case because multidisciplinary approach. The stronger point is that to start propranolol after pacemaker with good preparation and treatment of sepsis, with less tendency to interfere surgically. From this experience we recommend to good multidisciplinary approach with evidence-based intervention for such cases.

\section{References}

1. Smyth A, Garovic VD (2009) Systemic lupus erythematosus and pregnancy. Minerva Urol Nefrol 61: 457-474.

2. Bear R (1976) Pregnancy and lupus nephritis. A detailed report of six cases with a review of the literature. Obstet Gynecol 47(6): 715-718.

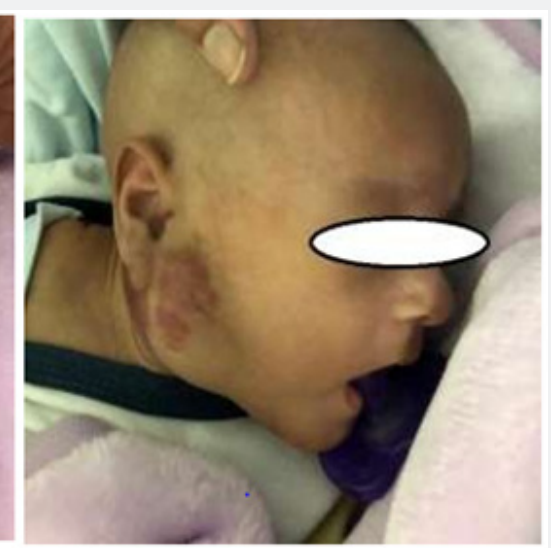

3. Le Thi Huong D, Wechsler B, Piette JC, Bletry O, Godeau P (1994) Pregnancy and its outcome in systemic lupus erythematosus. Qjm 87(12): 721-729.

4. Foocharoen C, Nanagara R, Salang L, Suwannaroj S, Mahakkanukrauh A (2009) Pregnancy and disease outcome in patients with systemic lupus erythematosus (SLE): a study at Srinagarind Hospital. J Med Assoc Thai 92(2): 167-174.

5. Kanada KN, Merin MR, Munden A, Friedlander SF (2012) A prospective study of cutaneous findings in newborns in the United States: correlation with race, ethnicity, and gestational status using updated classification and nomenclature. J Pediatr 2012;161(2): 240-245.

6. Kilcline C, Frieden IJ (2008) Infantile hemangiomas: how common are they? A systematic review of the medical literature. Pediatr Dermatol 2008;25(2): 168-173.

7. Drolet BA, Swanson EA, Frieden IJ, Hemangioma Investigator Group (2008) Hemangioma Investigator Group. Infantile hemangiomas: an 
emerging health issue linked to an increased rate of low birth weight infants. J Pediatr 153(5): 712-715.

8. Padmanaban S, Sumathi P, Prayagi Kandoth, Dharmendra RP (2017) Congenital capillary hemangioma arising from palpebral conjunctiva of a neonate. Indian J Ophthalmol 65(11): 1221-1223.

9. Chambers CB, Katowitz WR, Katowitz JA, Binenbaum GA (2012) Controlled study of topical $0.25 \%$ timolol maleate gel for the treatment of cutaneous infantile capillary hemangiomas. Ophthal Plast Reconstr Surg 28(2): 103-106.

10. Vassallo P, Forte R, Di Mezza A, Magli A (2013) Treatment of infantile capillary hemangioma of the eyelid with systemic propranolol. Am J Ophthalmol 155(1): 165-170.

11. Thoumazet F, Léauté-Labrèze C, Colin J, Mortemousque B (2012) Efficacy of systemic propranolol for severe infantile haemangioma of the orbit and eyelid: A case study of eight patients. Br J Ophthalmol 96(3): 370-374.

12. Missoi TG, Lueder GT, Gilbertson K, Bayliss SJ (2011) Oral propranolol for treatment of periocular infantile hemangiomas. Arch Ophthalmol 129(7): 899-903.

13. Brad B Kanski's (2016) Clinical Ophthalmology, ( $8^{\text {th }}$ edn), China: Elsevier, p. 101.

14. Schwartz SR, Kodsi SR, Blei F, Ceisler E, Steele M, et al.(2007) Treatment of capillary hemangiomas causing refractive and occlusional amblyopia. J AAPOS 11(6): 577-583.

15. Coats DK, O’Neil JW, D’Elia VJ, Brady-McCreery KM, Paysse EA (2003) SubTenon's infusion of steroids for treatment of orbital hemangiomas. Ophthalmology 110(6): 1255-1259.
16. Wilson MW, Hoehn ME, Haik BG, Rieman M, Reiss U (2007) Low-dose cyclophosphamide and interferon alfa 2 a for the treatment of capillary hemangioma of the orbit. Ophthalmology 114(5): 1007-1011.

17. Ooi KG, Wenderoth JD, Francis IC, Wilcsek GA (2009) Selective embolization and resection of a large noninvoluting congenital hemangioma of the lower eyelid. Ophthal Plast Reconstr Surg 25(2): 111-1114.

18. Jain V, Gordon C (2011) Managing pregnancy in inflammatory rheumatological diseases. Arthritis Research and Therapy 13: 206.

19. Lun Hon K, Leung AKC (2012) Neonatal lupus erythematosus. Autoimmune Diseases Article ID 301274: 6.

20. Izmirly PM, Kim MY, Llanos C, Le PU, Guerra MM, et al. (2010) Evaluation of the risk of anti-SSA/Ro- SSB/La antibody-associated cardiac manifestations of neonatal lupus in fetuses of mothers with systemic lupus erythematosus exposed to hydroxychloroquine. Annals of the Rheumatic Diseases 69(10): 1827-1830.

21. Ruiz-Irastorza G, Khamashta MA (2011) Lupus and pregnancy: integrating clues from the bench and bedside. Eur J Clin Invest 41(6): 672 678.

22. Madazli R, Yuksel MA, Oncul M, Imamoglu M, Yilmaz H (2014) Obstetric outcomes and prognostic factors of lupus pregnancies. Arch Gynecol Obstet 289(1): 49-53.

23. Pagani G, Reggia R, Andreoli L, Prefumo F, Zatti S, et al. (2015) The role of second trimester uterine artery Doppler in pregnancies with systemic lupus erythematosus. Prenatal Diagnosis 35(5): 447-452.

24. Clark CA, Spitzer KA, Nadler JN, Laskin CA (2003) Preterm deliveries in women with systemic lupus erythematosus. J Rheumatol 30(10): 2127-2132.

\section{Your next submission with Juniper Publishers will reach you the below assets}

- Quality Editorial service

- Swift Peer Review

- Reprints availability

- E-prints Service

- Manuscript Podcast for convenient understanding

- Global attainment for your research

- Manuscript accessibility in different formats

( Pdf, E-pub, Full Text, Audio)

- Unceasing customer service

Track the below URL for one-step submission

https://juniperpublishers.com/online-submission.php 